University of Nebraska - Lincoln

DigitalCommons@University of Nebraska - Lincoln

\title{
A relation between energies of the short-lived negative ion states and energies of unfilled molecular orbitals for a series of bromoalkanes
}

S. A. Pshenichnyuk

N. L. Asfandiarov

Paul Burrow

Follow this and additional works at: https://digitalcommons.unl.edu/physicsburrow

Part of the Atomic, Molecular and Optical Physics Commons

This Article is brought to you for free and open access by the Research Papers in Physics and Astronomy at DigitalCommons@University of Nebraska - Lincoln. It has been accepted for inclusion in Paul Burrow Publications by an authorized administrator of DigitalCommons@University of Nebraska - Lincoln. 


\title{
A relation between energies of the short-lived negative ion states and energies of unfilled molecular orbitals for a series of bromoalkanes
}

\author{
S. A. Pshenichnyuk, ${ }^{1}$ N. L. Asfandiarov, ${ }^{1}$ \& P. D. Burrow ${ }^{2}$
}
1 Institute of Physics of Molecules and Crystals, Russian Academy of Sciences, 151 prosp. Oktyabrya, 450075 Ufa, Russian Federation. email sapsh@anrb.ru 2 Department of Physics and Astronomy, University of Nebraska-Lincoln, Lincoln, NE 68588-0111, USA

\begin{abstract}
A series of bromoalkanes was investigated by means of electron transmission spectroscopy in the gas phase. Experimental values of vertical electron affinities associated with occupation of the LUMO by an incoming electron were assigned using ab initio quantum chemical calculations. The predicted vertical electron affinity values differ from measured ones by at most $\pm 0.2 \mathrm{eV}$.
\end{abstract}

Keywords: electron capture, vertical electron affinity, shape resonance, quantum chemical calculations.

Published in Russian Chemical Bulletin, International Edition, Vol. 56, No. 6, pp. 1268-1270, June, 2007. Published in Russian in Izvestiya Akademii Nauk. Seriya Khimicheskaya, No. 6, pp. 1222-1224, June, 2007.

Copyright (C) 2007 Springer Science+Business Media, Inc. Used by permission.

Submitted July 20, 2006; revised March 28, 2007 
T ow-energy $(\mathrm{o}-10 \mathrm{eV})$ electron scattering by molecules in the gas $\amalg$ phase leads to formation of short-lived $\left(10^{-15-10^{-10}} \mathrm{~s}\right)$ negative ion states by means of shape resonances. ${ }^{1}$ One of the most suitable methods for evaluation of the energies of these resonant states is electron transmission spectroscopy (ETS). ${ }^{2} A b$ initio calculations of the energies of normally unfilled molecular orbitals (MOs) associated with formation of the short-lived negative ions are usually utilized for assignment of the ETS data using the Koopmans' theorem approximation. ${ }^{3}$ The results of such calculations depend strongly on the basis set used, and it is necessary to apply the so-called scaling procedure to the calculated $\mathrm{MO}$ energies in order to estimate the negative vertical electron affinities of molecules. ${ }^{4}$ The predictions of the vertical electron affinities corresponding to resonant states associated with occupation of $\pi^{*}$-MOs by an incoming electron may be quite successful. The accuracy of such predictions using the scaling procedure is 0.1$0.3 \mathrm{eV}, 5$ i.e., close to experimental errors.

In the case of saturated compounds, only a few reports upon the relation between the calculated and experimental values of negative electron affinities for the resonances associated with occupation of the $\sigma^{*}$ _orbitals of chloro-substituted molecules are known. ${ }^{6,7}$ The investigation of the $\sigma^{*}$ orbitals of $\left(\mathrm{CH}_{3}\right)_{3} \mathrm{M}-\mathrm{M}^{\prime}\left(\mathrm{CH}_{3}\right)_{3}\left(\mathrm{M}, \mathrm{M}^{\prime}=\mathrm{Si}, \mathrm{Ge}, \mathrm{Sn}\right)$ has also been carried out. ${ }^{8}$ In this work, a series of bromoalkanes has been investigated and a relation between experimentally determined and calculated values Energy interrelations for bromoalkanes of the negative electron affinities of these molecules was established. The parameters for linear scaling of the virtual orbital energies (VOEs) to the energies of the negative ion states associated with occupation of the $\sigma^{*}{ }_{\mathrm{C}-\mathrm{Br}}-\mathrm{MO}$ were determined.

\section{Experimental}

Experiments were performed using the ETS technique in the format devised by Sanche and Schulz. ${ }^{2}$ A detailed description of the experimental setup and the operation conditions may be found in a review. ${ }^{9}$ Briefly, a magnetically collimated electron beam of well-defined energy was passed through a collision cell containing the target gas. The transmitted electron current was collected. To enhance resonant 
structures in the total electron scattering cross-section, the derivative technique ${ }^{9}$ was used. The vertical attachment energy (VAE, $\varepsilon_{\text {vert }}$ ), which is the negative of the vertical electron affinity, was assigned to the energy of the midpoint between two extrema appearing in the derivative of unscattered electron current because of the presence of a resonance peak in the total scattering cross-section. The electron energy scale was calibrated by a small admixture of $\mathrm{N}_{2}$ gas and referring to the sharp structure related to formation of the $\mathrm{N}_{2}{ }^{-}\left({ }^{2} \Pi_{\mathrm{g}}\right)$ state. Corresponding extrema in the derivative signal are found to be at 1.98, 2.22, 2.46, and $2.69 \mathrm{eV}$. The overall error in $\varepsilon_{\text {vert }}$ was $\pm 0.05 \mathrm{eV}$. Quantum chemical calculations were performed using the Gaussian ${ }^{\mathbf{1 0}}$ program. The optimization of molecular geometry and evaluation of the VOEs were performed by the Hartree-Fock (HF) ${ }^{11}$ and density functional theory ${ }^{\mathbf{1 2}}$ calculations using the $6-31 \mathrm{G}(\mathrm{d})$ basis set with no diffuse functions, because their inclusion leads to the breakdown of the correlation between experimental and calculated values. ${ }^{13}$ Compounds under investigation were purchased from Sigma-Aldrich.

\section{Results and Discussion}

The experimental $\varepsilon_{\text {vert }}$ values for the molecules under investigation compared with previous ETS data, and the calculated VOEs associated with the formation of corresponding negative ion states are listed in Table 1. The value for 1,2-dibromoethane is only an estimate because of strong overlapping of the resonant features in the ET spectrum corresponding to two lowest unoccupied MOs. This value was excluded from the linear approximation of the $\varepsilon_{\text {vert }}$ values as a function of VOEs. The best linear approach for other values is

$$
\varepsilon_{\mathrm{vert}}=\left(\varepsilon_{\mathrm{MO}}-3.23\right) / 0.99
$$

with a correlation coefficient of 0.91 for the HF/6-31G(d) calculations and

$$
\varepsilon_{\mathrm{vert}}=\left(\varepsilon_{\mathrm{MO}}+0.97\right) / 0.79
$$

with a correlation coefficient of 0.87 for the B3LYP/6-31G(d) level of theory. All the energies are in $\mathrm{eV}$. The estimated $\varepsilon_{\text {vert }}$ values obtained using these scaling equations are also listed in Table 1 in parentheses. 
Table 1. Negative ion state energies $\left(\varepsilon_{\text {vert }}\right)$ associated with occupation of the $\sigma^{*}{ }_{\mathrm{C}-\mathrm{Br}}-\mathrm{MO}$ by an incoming electron and energies of these orbitals $\left(\varepsilon_{\mathrm{MO}}\right)$ calculated for bromine-substituted alkane molecules.

\begin{tabular}{lccccc} 
& \multicolumn{2}{c}{$\varepsilon_{\text {vert }} / \mathrm{eV}$} & & \multicolumn{2}{c}{$\varepsilon_{\mathrm{MO}} / \mathrm{eV}$} \\
\cline { 2 - 3 } \cline { 5 - 6 } Compound & This work & Published data & & $\mathrm{HF} / 6-31 \mathrm{G}(\mathrm{d})$ & $\mathrm{B} 3 \mathrm{LYP} / 6-31 \mathrm{G}(\mathrm{d})$ \\
\hline 1-Bromoethane & 1.18 & $1.26^{14}$ & & $4.5413(1.32)^{*}$ & $0.112(1.37)$ \\
1-Bromopropane & 1.31 & $1.3^{15}$ & & $4.6056(1.39)$ & $0.154(1.42)$ \\
1-Bromobutane & 1.27 & $1.3^{15}$ & & $4.6083(1.39)$ & $0.151(1.42)$ \\
1-Bromopentane & 1.22 & - & & $4.6145(1.40)$ & $0.159(1.43)$ \\
2-Bromopropane & 1.21 & $1.23^{15}$ & & $4.5003(1.28)$ & $0.055(1.30)$ \\
2-Bromobutane & 1.18 & $1.25^{15}$ & & $4.4431(1.23)$ & $0.043(1.28)$ \\
tert-Butyl bromide & 1.09 & $1.09^{15}$ & & $4.3590(1.14)$ & $-0.075(1.13)$ \\
Dibromomethane & 0.26 & - & & $3.1879(-0.04)$ & $-1.073(-0.13)$ \\
& 2.00 & $1.93^{14}$ & & $4.8469(1.63)$ & $0.236(1.53)$ \\
1,2-Dibromoethane & $1.58^{* *}$ & - & $4.4875(1.27)$ & $0.224(1.51)$ \\
\hline
\end{tabular}

* Scaled MO energies are given in parentheses.

** An estimation. A method of evaluation of the overlapping features in the ET spectrum is described elsewhere. ${ }^{6}$

The parameters of the linear approximations have also been applied for estimation of $\varepsilon_{\text {vert }}$ in a series of related bromo-substituted compounds. Corresponding data are listed in Table $\mathbf{2}$ in parentheses.

With very few exceptions the estimated and experimental $\varepsilon_{\text {vert }}$ values differ by at most $\pm 0.2 \mathrm{eV}$, which is practically comparable with experimental errors of $0.05-0.1 \mathrm{eV}$. There is a considerable difference between the estimated and experimental $\varepsilon_{\text {vert }}$ energies in the case of bromomethane with both HF and DFT methods. Most probably, the calculation fails to agree in this case, as it was reported for chloromethane. ${ }^{6}$ The ET spectrum of bromomethane, in common with that of chloromethane, has a quite broad $(>2.5 \mathrm{eV})^{\mathbf{1 4}}$ feature that may be distorted by the variations in the non-resonant portion of the scattering cross-section. This may make difficulties in evaluation of the experimental VAE. The slope of the linear correlation obtained in this work (1.01 at the HF/6-31G(d) level of theory) is close to the value of 0.91 obtained ${ }^{6}$ for the $\sigma^{*}{ }_{\mathrm{C}-\mathrm{Cl}}-\mathrm{MOs}$ of chloroalkanes calculated at the same level of theory. However, the scaling parameters for the $\sigma^{*}-\mathrm{MO}$ energies found in Ref. 8 are quite different (the slope is 1.52). Thus, the correlations obtained in this work are applicable to structurally 
Table 2. Negative ion state energies $\left(\varepsilon_{\text {vert }}\right)$ associated with occupation of the $\sigma^{*}{ }_{\mathrm{C}-\mathrm{Br}}-\mathrm{MO}\left(\varepsilon_{\mathrm{vert}}\right)$ by an incoming electron and corresponding MO energies $\left(\varepsilon_{\mathrm{MO}}\right)$ calculated for previously studied molecules.

\begin{tabular}{lccc} 
& $\varepsilon_{\text {vert }} / \mathrm{eV}$ & \multicolumn{2}{c}{$\varepsilon_{\mathrm{Mo}} / \mathrm{eV}$} \\
\cline { 2 - 4 } Compound & & $\mathrm{HF} / 6-31 \mathrm{G}(\mathrm{d})$ & $\mathrm{B} 3 \mathrm{LYP} / 6-31 \mathrm{G}(\mathrm{d})$ \\
\hline $\mathrm{MeBr}$ & $2.4^{14}$ & $4.484(1.27)$ & $0.079(1.33)$ \\
$\mathrm{CHBr}_{3}$ & $0.85^{14}$ & $4.194(0.97)$ & $-0.333(0.81)$ \\
$\mathrm{CBr}_{4}$ & $0.42^{14}$ & $3.586(0.36)$ & $-0.838(0.17)$ \\
$\mathrm{PhBr}$ & $<1.8^{16}$ & $4.614(1.40)$ & $0.199(1.48)$ \\
$\mathrm{PhCH}{ }_{2} \mathrm{Br}$ & $2.26^{16}$ & $5.224(2.01)$ & $0.826(2.27)$ \\
Bromocyclopropane $_{\text {Bromocyclopentane }}$ & $1.2 \mathrm{O}^{15}$ & $4.541(1.32)$ & $0.120(1.38)$ \\
Bromocyclohexane $_{\mathrm{CH}_{2}=\mathrm{CH}\left(\mathrm{CH}_{2}\right)_{3} \mathrm{Br}}^{1.20^{15}}$ & $4.554(1.34)$ & $0.099(1.35)$ \\
$\mathrm{CH}_{2}=\mathrm{CH}\left(\mathrm{CH}_{2}\right)_{4} \mathrm{Br}$ & $1.30^{15}$ & $4.473(1.26)$ & $0.109(1.37)$ \\
\hline
\end{tabular}

* An estimate.

similar molecules and in the case of electron attachment to the $\sigma^{*}{ }_{\mathrm{C}-\mathrm{Br}} \mathrm{MO}$. Analogous restrictions have also been found in the case of predictions of the VAEs associated with occupation of $\pi^{*}$-MOs by an incoming electron. ${ }^{6-8}$

It should be noted that for bromoalkanes under investigation the correlation coefficients (0.91 and o.87) are smaller not only compared with those found for $\pi^{*}$-MOs (about 0.99 with both $\mathrm{HF}^{5}$ and DFT 7 methods), but also with those (about $0.98^{8}$ ) found for $\sigma^{*}$-MOs in other families of saturated systems. A possible reason is that the experimental VAEs of the monobromo-substituted compounds lie in a very narrow energy range (about $1.3 \mathrm{eV}$ for the $n$-alkanes and 1.2 eV for the secondary alkanes). Thus, there is an indeterminacy in the slope of the linear regression. In the dibromo-substituted compounds the VAEs change, but overlap of the broad features in the spectrum makes accurate location of the VAEs difficult. In conclusion, it should be noted that estimations of molecular electron affinity by the total energy difference between the molecule and corresponding radical anion are mostly performed in the case of calculation of adiabatic electron affinities, ${ }^{17}$ being more reliable in the case of its positive value. ${ }^{18}$ The shape resonance energies, which may not be associated with occupation of the LUMO by an incident electron, can more conveniently 
be evaluated by MO energy calculations using the Koopmans' theorem approximation followed by applying the scaling procedure; this allows saving the computing time as well.

Acknowledgments The authors are grateful to Prof. Alberto Modelli for helpful discussions of the results. This work was financially supported by the Russian Foundation for Basic Research (Project No. o6-03-32059-a).

\section{References}

1. G. J. Schulz, Rev. Mod. Phys., 1973, 45, 423.

2. L. Sanche and G. J. Schulz, Phys. Rev. A, 1972, 5, 1672.

3. T. Koopmans, Physica (Amsterdam), 1934, 1, 104.

4. D. Chen and G. A. Gallup, J. Chem. Phys., 1990, 93, 8893.

5. S. W. Staley and J. T. Strnad, J. Phys. Chem., 1994, 98, 116.

6. K. Aflatooni, G. A. Gallup, and P. D. Burrow, J. Phys. Chem. A, 2000, 104, 7359.

7. A. Modelli, Phys. Chem. Chem. Phys., 2003, 5, 2923.

8. A. Modelli and L. Szepes, Chem. Phys. Lett., 2003, 286, 165.

9. K. D. Jordan and P. D. Burrow, Chem. Rev., 1987, 87, 557.

10. M. J. Frisch, G. W. Trucks, H. B. Schlegel, G. E. Scuseria, M. A. Robb, J. R. Cheeseman, J. A. Montgomery, Jr, T. Vreven, K. N. Kudin, J. C. Burant, J. M. Millam, S. S. Iyengar, J. Tomasi, V. Barone, B. Mennucci, M. Cossi, G. Scalmani, N. Rega, G. A. Petersson, H. Nakatsuji, M. Hada, M. Ehara, K. Toyota, R. Fukuda, J. Hasegawa, M. Ishida, T. Nakajima, Y. Honda, O. Kitao, H. Nakai, M. Klene, X. Li, J. E. Knox, H. P. Hratchian, J. B. Cross, C. Adamo, J. Jaramillo, R. Gomperts, R. E. Stratmann, O. Yazyev, A. J. Austin, R. Cammi, C. Pomelli, J. W. Ochterski, P. Y. Ayala, K. Morokuma, G. A. Voth, P. Salvador, J. J. Dannenberg, V. G. Zakrzewski, S. Dapprich, A. D. Daniels, M. C. Strain, O. Farkas, D. K. Malick, A. D. Rabuck, K. Raghavachari, J. B. Foresman, J. V. Ortiz, Q. Cui, A. G. Baboul, S. Clifford, J. Cioslowski, B. B. Stefanov, G. Liu, A. Liashenko, P. Piskorz, I. Komaromi, R. L. Martin, D. J. Fox, T. Keith, M. A. Al-Laham, C. Y. Peng, A. Nanayakkara, M. Challacombe, P. M. W. Gill, B. Johnson, W. Chen, M. W. Wong, C. Gonzalez, and J. A. Pople, Gaussian 03, Revision B.o1, Gaussian Inc., Pittsburgh (PA), 2003.

11. J. A. Pople, Usp. Fiz. Nauk, 2002, 172, 349 [Physics-Uspekhi, 2002, 172 (Engl. Transl.)].

12. W. Kohn, Usp. Fiz. Nauk, 2002, 172, 336 [Physics-Uspekhi, 2002, 172 (Engl. Transl.)].

13. N. Heinrich, W. Koch, and G. Frenking, Chem. Phys. Lett., 1986, 124, 20. 
14. A. Modelli, F. Scagnolari, G. Distefano, D. Jones, and M. Guerra, J. Chem. Phys., 1992, 96, 2061.

15. A. Modelli and D. Jones, J. Phys. Chem. A, 2004, 108, 417.

16. A. Modelli, J. Phys. Chem. A, 2005, 109, 6193.

17. J. C. Rienstra-Kiracofe, G. S. Tschumper, and H. F. Schaefer, III, Chem. Rev., 2002, 102, 231.

18. A. Modelli, L. Mussoni, and D. Fabbri, J. Phys. Chem. A, 2006, 6482. 